\title{
Development and Validation of the Information Systems Creative Self- Efficacy Scale
}

\author{
Katherine Carl Payne \\ University of the \\ Incarnate Word \\ kcpayne@uiwtx.edu
}

\author{
Mark J. Keith \\ Brigham Young \\ University \\ mark.keith@gmail.com
}

\author{
Jeffry Babb \\ West Texas A\&M \\ University \\ jbabb@wtamu.edu
}

\author{
Alexandra N. Spruill \\ Brigham Young \\ University \\ alex.spruil195@gmail.com
}

\begin{abstract}
High-performing information systems (IS) professionals harness creativity as they build systems to solve new and unstructured business problems. Psychology has developed useful scales and techniques for measuring creativity. However, "being creative" is not sufficient. IS professionals must also have confidence in their creative ability to succeed. The belief in one's ability to be creative is termed creative self-efficacy (CreaSE). CreaSE is defined in the general business context, but scales are not thoroughly developed or refined. CreaSE has also never been studied in the IS context. We detail steps to develop and validate a theoretically-based measure of CreaSE as related to IS. Our process includes six datasets collected during refinement. Participants include business and IS students, online respondents, university professors, IS executives, and IS professionals. The validated instrument is a secondorder formative measure with reflective first-order sub-constructs based on belief in cognitive ability, affect, domain knowledge, skills, and understanding of people.
\end{abstract}

\section{Introduction}

One of the key characteristics of high performing information systems (IS) professionals is their ability to be creative as they build systems to solve new or unstructured business problems [13, 53]. Psychology research has developed a variety of useful scales and techniques for measuring individual creativity [e.g., 17]. However, it is not enough to merely "be" a creative person. A good IS professional must also have confidence in their own creative ability to reach their potential. Otherwise, they may not put forth the "coping" efforts needed to solve problems. Indeed, sometimes the belief in one's abilities has a greater effect on performance than one's actual ability [6].

Bandura theorizes this belief in one's abilities as "self-efficacy" [3]. Self-efficacy theory-based on social learning theory [5]—posits that self-efficacy determines the level of effort we will expend on certain tasks. As a result, self-efficacy also affects our performance on these tasks. Self-efficacy has been applied in a variety of IS contexts, including computer self-efficacy [11], internet self-efficacy [26], mobile selfefficacy [29], and many others. In general, greater selfefficacy in these contexts leads individuals to try both harder and more tenaciously to complete tasks that require computers, Internet, and mobile devices, etc.

However, the creativity needed to solve complex and unstructured IS problems requires more than just a knowledge of and skill-base in various technologies. IS professionals must also understand business processes and strategy as well as how people will interact with technology to support those processes [24, 25]. Therefore, judging an IS professional's or student's ability to solve unstructured IS problems based only on their self-efficacy with specific technologies would provide only a limited view.

The relevance of creativity to the problems of IS design and use can be understood via the roles that imagination and creativity have played in the harnessing of important trends. Thus, while the advantages of copious computing are requisite for contemporary and future systems success, the additional requirement for resonance is also compelling: there are myriad competencies that factor into successful IS professionals, and creativity may be the most compelling. To wit, many have questioned a rush to STEM and data analytics when a concomitant commitment to human resonance with the IS problems we define and the solutions we craft is diminished, obscured, or omitted [39].

We posit that creativity is a primary facet of IS professionals' competencies, as those who can utilize reflection, imagination, and innovation with technical excellence may flourish solving future IS problems. However, creativity alone is insufficient to ensure success. Rather, self-assurance and faith in one's ability to effectively summon creativity in nascent contexts creates the inertia necessary to capitalize on creativity.

Management research has defined a construct termed creative self-efficacy (CreaSE) as an employee's belief in their ability to creatively solve problems [52]. While this line of research has shown promising results for explaining employee productivity, the commonly accepted measure of CreaSE only refers to the general management context and is not well-suited to the unique 
IS discipline, which requires expertise in a combination of technology, business processes, and human behavior [7, 24, 25]. Furthermore, there has not been a rigorous scale development and refinement process for this construct in the management discipline based on the strongest principles for scale development [c.f. 33]. In summary, CreaSE has received limited attention (with exception [50]) in the IS context overall.

To contribute to this body of literature, this paper details the steps taken to develop and validate a theoretically-based measure of CreaSE as it relates to the IS field. Following detailed procedures outlined for construct development [33], we specify CreaSE as a second order formative construct with five reflective sub-constructs based on an individual's belief in their (1) cognitive ability, (2) domain knowledge, (3) training (including business, technology, and data skills), (4) "people" skills, and (5) affect toward creative problem solving. Our validation process includes six distinct data collections across a variety of populations — including business students, IS students, business professionals, IS professionals, executives, and university professors - which allowed us to repeatedly refine the scale. In addition, we validate our instrument in a nomological model that predicts coping efforts and performance on creative tasks.

\section{Creative Self-Efficacy}

Tierney and Farmer [52, p. 1138] were the first to define CreaSE as "the belief one has the ability to produce creative outcomes." Based on relevant psychology literature on creativity, they created the following four-item measure: I have confidence in my ability to solve problems creatively, I feel that I am good at generating novel ideas, I have a knack for further developing the ideas of others, and I am good at finding creative ways to solve problems.

\subsection{CreaSE Research Findings}

Tierney and Farmer demonstrated that CreaSE does lead to actual job performance on creative tasks as measured by supervisors. Their measure has been used by many researchers in other management [44] and educational contexts [7] and also to further the work on CreaSE itself [19].

Whereas actual job performance on creative tasks is a significant consequence of CreaSE, perceived job performance is an antecedent of CreaSE [52]. However, job self-efficacy and CreaSE are distinct constructs as employees can have high job selfefficacy and low CreaSE. Other antecedents of CreaSE include supervisor support and job complexity
[52].

Gong et al. (2009) extended this work by measuring CreaSE as both a mediating and moderating variable. They found that CreaSE mediates the effect of transformational leadership and employee learning orientation on job performance. In other words, there are certain learning styles that are conducive to developing CreaSE and strong leaders may also improve CreaSE. In addition, research has shown that CreaSE can be improved through training [9].

Furthering their research on CreaSE, Tierney and Farmer [51] later showed that CreaSE improves when given opportunities for creativity as well as supervisor expectations. Thus, CreaSE changes over time.

\subsection{Alternative Measurements of CreaSE}

Other researchers have worked to expand and improve Tierney and Farmer's original four-item measure. Yu [55] added several additional items to capture a person's belief in their talent/expertise and attitude toward creativity. Interestingly, their exploratory factor analysis (EFA) revealed two sub-dimensions of CreaSE which were labeled "creative intentions" and "creative behaviors." Upon examining the actual items, those which loaded on the creative intentions sub-construct may be more indicative of a true self-efficacy measure because they use words pertaining to a person's belief about their abilities. Those that loaded on the "creative behaviors" subconstruct were better framed as self-reported behaviors rather than actual self-efficacy.

Choi [10] developed his own four-item measure of CreaSE and also demonstrated that it affects performance on creative tasks. However, CreaSE is also determined by actual creative ability and what they termed a "cautious personality."

Yang and Cheng [54] adapted CreaSE to the IS field. However, their measure consisted of 13 items based on Zhou and George's [56] reflective measure of creativity (as opposed to CreaSE) with the adaptation of basing the items on the employee's "belief in their ability to...". This measure included several new dimensions that are useful to both the general business and IS contexts. For example, their items included additional measures of an employee's belief in their attitude toward creativity, information search skills, and "people" skills. These thirteen items were modeled as a first order reflective construct. Yang and Cheng demonstrated the effects of several antecedents to CreaSE. First, computer self-efficacy and other domain-specific IT skills led to greater CreaSE. Second, they also measured advice network centrality in terms of how "well-connected" an employee is in the advice network and the strength of those relationships. Strong advice-sharing relationships correlated with greater CreaSE while more advice-sharing relationships 
were associated with less CreaSE. This may be an indication that young employees are sought out for advice less often by co-workers.

In summary, this prior research on CreaSE provides a solid foundation to draw from. However, there are several ways in which this work and the measurement scales developed can and should be improved. First, most of the measures created have only been tested for reliability based on Cronbach's alpha $(\alpha)$ [46]. This is a limitation because Cronbach's alpha does not indicate discriminant validity and essentially represents only the "lower bound" of reliability [12]. Second, although two studies measuring CreaSE did perform an EFA, one of them did not report the results [52], and the other indicates clear sub-dimensions of CreaSE, yet treated the subdimensions as separate independent variables rather than modeling them with a second-order factor [55]. Third, self-efficacy has typically been argued to be a formative rather than reflective construct [34, 35]. Upon examining Tierney and Farmer's original items, this appears to be also true in the context of CreaSE. For example, one could feel they are good at developing their own creative ideas, yet also believe they are not so good at building on the creative ideas of others. When other dimensions of creativity are included, like one's belief in knowledge and skills [e.g., 55], the likelihood that each dimension of creativity varies independently increases.

Therefore, to improve the measurement of CreaSE, we proceed by reviewing relevant theory on creativity, self-efficacy, and the IS discipline and context.

\section{Theoretical Basis for CreaSE}

\subsection{Creativity}

Creativity research has been refined over decades. As a result, there is a rich base of theory to draw from. We adopt the "systems" view of creativity that has been established in recent reviews of creativity research [22]. In particular, the systems view frames creativity at various interacting levels within a system (see Figure 1 adapted from [22]).

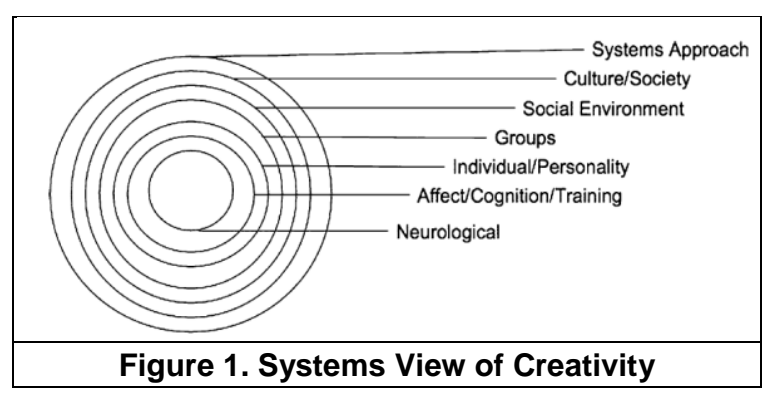

The base of creativity begins at the neurological level. Functional magnetic resonance imaging (fMRI) technology has made it possible to examine how blood flows through the brain to enable creativity [36]. Although the neurological level cannot be measured through a survey, our brain make-up does determine other important factors that have each been identified in creativity research: affect, cognition, and training.

Affect refers to our emotions, moods, and attitude [8]. These can have a significant effect on our creative performance. For example, negative affect can reduce our "flexible thinking" and problem solving capabilities on complex tasks [27]. Affect is determined by the chemical processes in our brain; making it an "outer" layer to the neurological layer.

Cognition is perhaps the concept that we most closely associate with creativity. Cognition refers to our ability to learn and acquire knowledge through thoughts, experiences, and senses [20]. Cognition is also used to refer to our general intelligence factor (e.g. IQ score). However, the cognitive mechanisms that determine creative performance are domain-specific [28]. Thus, domain knowledge and training are also relevant.

Training refers to the knowledge we develop and store in memory. Knowledge can be either declarativeknowledge "about" something like rules and requirements - or procedural-knowledge of "how to do" something, like ride a bike [1]. There are many types of training relevant to the IS context (discussed more later) that involve some combination of both declarative and procedural knowledge. In general, research has demonstrated that carefully constructed training that focuses on realistic exercises and scenarios can improve creative performance [48].

Affect, cognition, and training interact with the characteristics of our personality that may enable or limit our ability to be creative. The "Big Five" personality model has shown the most promise in determining creativity and the "openness to experience" factor in particular [42]. Other research has examined personality traits such as self-confidence [28], which is at the heart of self-efficacy theory [5] discussed later.

Individual personalities also interact with the group level as groups' creative individuals work on tasks. Groups interact with the social environment, which interact with the societal culture. However, the focus of this research is developing a measure of CreaSE in the IS context at the individual level. In addition, a scale developed would be in the form of a questionnaire rather than an fMRI technique that examines neurological structure. Therefore, we restrict the scope of our measure to affect, cognition, and training (which will be expanded next). 


\subsection{Information Systems Discipline}

As discussed above, the training that influences creativity must be specific to its domain [22]. Therefore, we next base the domain context firmly in the IS discipline and define exactly what types of "training" (referred to in creativity theory [22]) are relevant to IS. To accomplish this, we draw from core concepts on the IS discipline [24, 25] to identify three specific types: (1) business knowledge of processes, strategy, and management, (2) skills with technology development, data analytics, and solution implementation, and (3) understanding of how people will respond to and interact with technology.

The distinction between 1 and 2 above is important because, perhaps more so than other areas of a business, IS requires not only declarative knowledge, but also procedural knowledge used to perform tasks like software development and hardware installation. However, it may also be argued that any measure of CreaSE in a business context should involve these same three types of training depending on the specificity of the technology skills.

The unique training and skills of the IS discipline are accompanied by domain-specific cognitive ability. How adeptly an individual learns from reason and sensory experience often depends on the context [41]. While general intelligence is an indicator of broad cognitive ability, domain-specific intelligence provides more accurate insight into a person's cognitive ability within the domain. With respect to our model, cognitive ability within the IS discipline affects performance and coping ability while attempting to solve IS problems using IS skills. In the infancy of the field, successful IS professionals came from various backgrounds (managerial and technical) with no apparent difference in performance [31]. However, maturation within the IS field over time has led to technical competence and cognitive ability that is domain-specific [37]. There has been a demand for technically-minded professionals in IS that can design interfaces that encapsulate the underlying technology and innovate and exploit new IT capabilities [37]-a way of thinking not required of general management.

It has also been suggested that affect is domainspecific in academic contexts, supporting our inclusion of affect in a model of CreaSE specific to IS [19].

As the IS discipline evolves into a future shaped by consequences of pervasive and ubiquitous computing not yet experienced or entirely conceptualized, both creativity and high CreaSE will be requisite competencies for practitioners moving forward. Problem-setting and -solving [47] in the next era of the IS discipline is likely to require proclivities that extend beyond learned/acquired skill and raw cognition; any skill that lends itself to computation will no longer be within the sole purview of human competency [32]. Rather, the need to understand how the IS discipline will cope with expanding complexity in the problem spaces related to skills, and people, suggests human creativity as a compelling subject for scholarly investigation. Moreover, a better understanding of CreaSE may provide the lens through which we may grasp how and why the discipline will evolve to match the ever-emergent computing, organizational, and information environment.

\subsection{Self-Efficacy}

Finally, we draw from self-efficacy theory to place the components of creativity and the IS domain into a core theoretical model. The self-efficacy construct is derived from social cognitive theory [5, 3]. SCT explains how people learn and develop based on their environment, cognition, and behavior and how human learning and personality are developed based on observation of others, self-regulation, self-reflection, and self-efficacy.

Self-efficacy beliefs are "people's judgements of their capabilities to organize and execute a course of action required to attain designated types of performances" [4, p. 391]. In other words, if I have high self-efficacy toward a task, then I judge myself competent and capable "enough" to complete that task. As a result, self-efficacy determines both the "coping efforts" we expend on tasks as well as our actual performance on that task-to the degree that our coping efforts affect the task.

In summary, we examine self-efficacy because solving unstructured or new problems requires more than simply being a creative person. One must also possess the confidence that they can solve the problem or they won't put forth the effort required to solve it. According to Bandura [3], observation, training, and past performance increase self-efficacy, which, in turn, increases coping efforts which, in turn, increase performance on a task.

Self-efficacy is the theoretical lens that we adapt creativity into. The self-efficacy lens is important to this research because it frames both (1) the nature of the CreaSE measure as well as (2) the expected antecedents and consequences. First, because CreaSE is a measure of self-efficacy in a particular task, the measurement items will be based on the individual's belief in their ability to be creative problem solvers [2]. This often results in items beginning with "I believe I have the ability to..." This means that the items reflect an individual's expected performance on future tasks rather than their perceived past behaviors [e.g., 55]. Second, we can map the prior research findings on antecedents and consequences of CreaSE into those specified in self-efficacy theory (see Figure 2). 


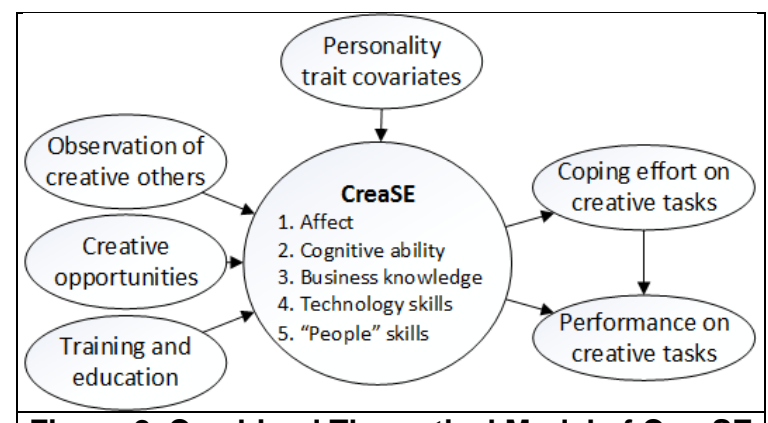

Figure 2. Combined Theoretical Model of CreaSE

It should be noted that although personality traits are relevant indicators of creativity [22], we do not include them as sub-dimensions of the CreaSE construct because, according to self-efficacy theory [3], personality is a separate construct that affects, and is affected by, our developed self-efficacy. Therefore, we include it as a covariate in the nomological CreaSE model rather than as a sub-dimension of CreaSE.

In summary, a complete measure of CreaSE based on creativity theory and the IS discipline should include sub-constructs based on individual (1) affect, (2) cognitive ability, and three types of training: (3) business knowledge, (4) technology skills, and (5) "people" skills. Based on the preceding review, we formally define CreaSE in the IS context:

.... an individual's belief in their ability to develop creative solutions to new or unstructured business problems through the development of information systems that support business process and the people who execute them.

\section{Methodology}

In order to generate a valid instrument, we followed the rigorous procedures and methodology outlined by MacKenzie et al. [33, pg. 297]. This methodology includes ten steps that we follow in detail through the remainder of this paper: 1) form a conceptual definition of the construct (see above), 2) generate items, 3) assess content validity, 4) specify the measurement model, 5) collect data to pre-test, 6) scale refinement, 7) gather new sample and reexamine scale properties, 8) assess scale validity (repeat 6-8 as needed), 9) cross-validate the scale with samples from different populations, and 10) develop scale norms.

Steps 2-10 were executed based on six unique data collections administered to various combinations of IS executives, IS professors, IS students, IS professionals, general business students, Amazon Mechanical Turk (AMT) master workers (validity established in [40]), and general business professionals across the US randomly selected by
Qualtrics. Table 1 summarizes the total sample sizes, demographics, and purposes of each data collection which will be further explained throughout this section.

\begin{tabular}{|c|c|c|c|c|c|c|c|c|}
\hline \multicolumn{9}{|c|}{ Table 1. Demographic Statistics } \\
\hline $\begin{array}{l}\text { Data } \\
\text { collecti } \\
\text { on: }\end{array}$ & $\begin{array}{l}\text { Pre- } \\
\text { test }\end{array}$ & CAT1 & CAT2 & CAT3 & $\begin{array}{c}\text { IS } \\
\text { stud- } \\
\text { ents }\end{array}$ & $\begin{array}{l}\text { Bus. } \\
\text { stud- } \\
\text { ents }\end{array}$ & $\begin{array}{l}\text { Bus. } \\
\text { pro. }\end{array}$ & IS pro. \\
\hline $\mathrm{N}$ & 180 & 461 & 467 & 482 & 264 & 530 & 200 & 119 \\
\hline Source & \multicolumn{4}{|c|}{ AMT } & ${ }^{*} \dagger$ & * & Q & ** \\
\hline Female & \multicolumn{4}{|c|}{$35.7 \%$} & $19 \%$ & $27 \%$ & $48 \%$ & $10 \%$ \\
\hline Age & \multicolumn{4}{|c|}{30.0 years average } & $18-24$ & $18-24$ & $35-44$ & $25-29$ \\
\hline $\begin{array}{l}\text { Non- } \\
\text { white }\end{array}$ & \multicolumn{4}{|c|}{$38.3 \%$} & $15 \%$ & $12 \%$ & $61 \%$ & $14 \%$ \\
\hline Income & \multicolumn{4}{|c|}{$61 \mathrm{k}$ per year } & $<30 \mathrm{k}$ & $<30 k$ & $>80 \mathrm{k}$ & $>100 \mathrm{k}$ \\
\hline $\begin{array}{l}\text { Yrs of } \\
\text { college }\end{array}$ & \multicolumn{4}{|c|}{ 2-4 college degree } & $<4$ & $<4$ & 4 & 6 \\
\hline \begin{tabular}{|l|} 
Yrs \\
work
\end{tabular} & \multicolumn{4}{|c|}{4 years full time } & $1-3$ & $1-3$ & $10+$ & $5-10$ \\
\hline
\end{tabular}

Notes: *These students were enrolled in a large private university in the western US. † These students were enrolled specifically in the IS undergraduate major and were working in a technical programming course. $\mathrm{Q}=$ a professionally collected random sample (via Qualtrics) of US employees with at least 3 years of full-time work experience and a 2-year college degree. Variety = employees currently working in IS related job roles from Ernst \& Young, Pariveda Solutions, Price Waterhouse Coopers, Microsoft, and a variety of other major consulting and IS firms (of those who chose to disclose their company).

\section{Results}

\subsection{Item Generation and Content Validity}

Steps 2 and 3 were performed somewhat iteratively and in concert with each other. After identifying the subconstructs above from literature on creativity $[22,7,9,10$, $13,36,44,53]$, and before actually generating the constructs, we surveyed IS executives contacted through the advisory boards of two universities and IS faculty across four universities. The survey included two openended questions designed to gather valid content from both educators and professionals in the IS field. The questions were, "What high level qualities/attributes would you look for in a candidate when hiring an IS professional? Please list them in order of importance (highest to lowest) as much as possible" and "In the previous question, you may have included a response concerning the ability of candidates to be creative in their use of information technology to solve business problems. If you did not already include it in that rank-ordered list, and if you agree that it is important, where would you rank it in that list in retrospect?" These questions were modified slightly for the academic context as well.

The purpose was to see if practitioners generated similar sub-constructs to those we identified from theory as well as to see how important creativity is in general. 
The qualitative responses mapped very well to the subconstructs developed above. Therefore, we generated 21 items across five sub-dimensions that captured both the qualitative responses and the theoretical dimensions. As noted later, these were eventually divided into five separate sub-constructs.

The items created were then given back to twenty members of an IS advisory board for review. No major modifications were made-likely because the items already reflected their input-but several minor edits were made for clarity. For space issues, we will only report the final items later.

\subsection{Formally Specify the Measurement Model}

Mackenzie [33, p. 302] argues that constructs are not inherently formative or reflective. Rather, measures can be modeled depending on the theoretical expectations. Generally, technology-based selfefficacy measures have been modeled formatively because a person may have confidence in their ability to use one technology, but not another [34, 35]. Creativity is a somewhat broader domain than computers, Internet, or mobile devices alone. Rather it encompasses a variety of technology skills, people skills, business skills and knowledge, cognition, and affect.

These individual sub-constructs may vary independently of each other. Therefore, it is likely that some level of CreaSE should be formative. However, within each sub-construct, the items we created represent a reflection of an individual's overall confidence in that topic. Therefore, we model CreaSE as a second order factor where the first order subconstructs are reflective and the second order construct is formative. As a result, we will use validation techniques suitable to reflective measures only at the first order and different validation for the second-order formative construct. However, because three of the sub-constructs (business knowledge, skills, people understanding) were generated from the same concept of training from the creativity literature, we will examine the possibility of both a second order reflective construct and a third order formative (see Figure 3). As will be explained later, we retained the second-order reflective model because of slightly better fit statistics.

\subsection{Collect Data to Conduct Pretest}

To conduct a pre-test of these items, 180 participants were recruited using Amazon Mechanical Turk (AMT) - knowing that the items were likely to go through multiple iterations of refinement. In addition to the CreaSE scale, we also created scales to measure individual's perceived coping effort and performance on creative tasks (consequences of CreaSE) as well as their opportunities for observing other creative individuals and formal training on business knowledge and skills (antecedents). Several demographic variables were collected including age, gender, income, education, relationship status, work experience, and length of employment. Lastly, the existing scales were used to collect personality trait covariates including openness to experience [18] and risk aversion [38].

All items were randomized across all scales. For the pre-test and all other collections, we removed responses due to missing trap questions, "straight-lining," or taking fewer than 3.4 minutes on the survey (1/3 of the median response time is the recommended industry standard).

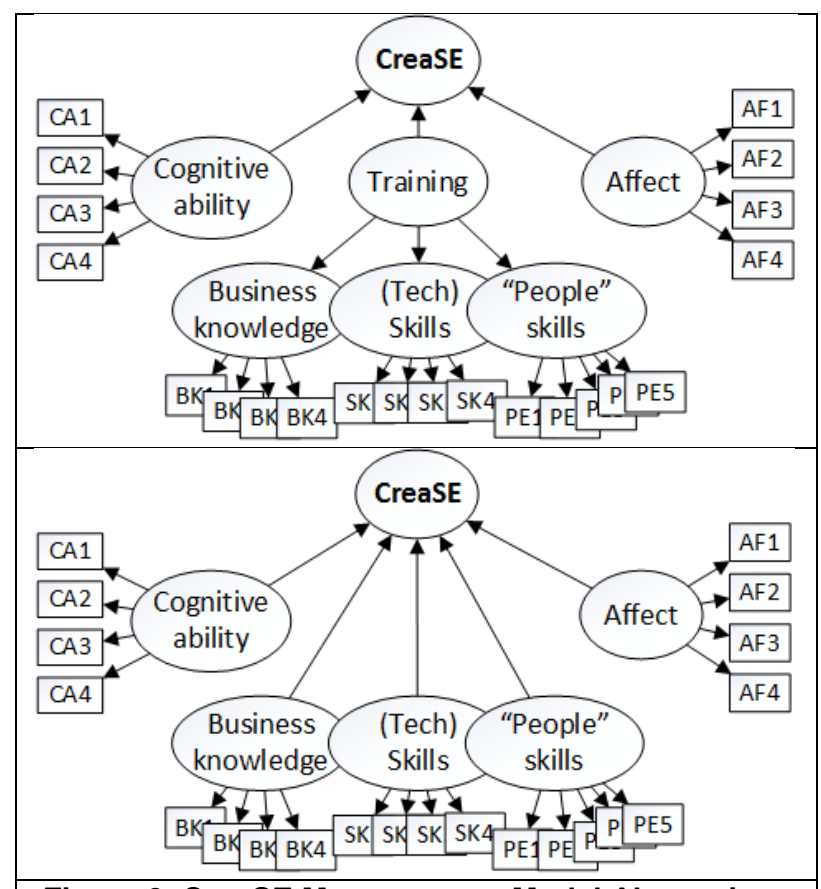

Figure 3. CreaSE Measurement Model Alternatives

\subsection{Assess the Validity of Pretest Data}

Next, MacKenzie et al. [33] recommend performing an EFA on the pretest data and evaluating reliability, convergent validity, and discriminant validity. The EFA revealed only one large factor regardless of the method of extraction or rotation. This indicates that either our data exhibited strong common methods bias (CMB) [43] or that there was little separation among sub-constructs.

The measurement model fit was analyzed using a confirmatory factor analysis (CFA). Interestingly, the CFA based on the second-order model of CreaSE (i.e., the bottom image in Figure 3) indicated a moderate to poormoderate model fit with a significant chi-square statistic 
$(\mathrm{p}<0.001), \mathrm{GFI}=0.829, \mathrm{CFI}=0.925$ and $\mathrm{RMSEA}=$ 0.088 [33]. These fit statistics were slightly better than those of the third-order model; therefore, we retained the second-order model.

Reliability for each scale was analyzed by measuring Cronbach's alpha for each of the subdimensions which was well-above the 0.7 threshold ranging from 0.79 to 0.93 . To evaluate the reliability of each individual scale item, we examined the significance of the estimate $(\lambda)$ of the relationship between an indicator and the latent construct. All items were significant.

Convergent validity was analyzed by calculating the average variance extracted (AVE) for each firstorder reflective sub-construct. All AVEs were wellover the 0.50 recommended cutoff [16] ranging from 0.62 to 0.71 . We did not calculate AVE at the secondorder level because it is not relevant for formative constructs. Rather, Edwards [14] adequacy coefficient $\left(\mathrm{R}_{\mathrm{a}}^{2}\right)$ should be greater than 0.50 to indicate "that, on average, a majority of the variance in the indicators is shared with the construct" [33, p. 313]. This score was 0.91 for this data. In summary, the data exhibits convergent validity.

Discriminant validity was analyzed by examining whether the average variance explained (AVE) by the indicators for their underlying latent constructs is greater than the squared correlation between the focal construct and the other sub-constructs [16]. This test revealed several serious problems. In particular, the scales for cognitive ability, business knowledge, and skills did not discriminate among each other at all.

In summary, although our initial items demonstrated adequate, but low, model fit, good reliability, and good convergent validity, there was clearly cause for concern with $\mathrm{CMB}$ and discriminant validity. To improve the content of the items and the discriminant validity, we implemented what MacKenzie et al. [33] termed as the "content adequacy test" which was created by Hinkin and Tracey [23] but has rarely been used in IS research until recently [49]. This test is very useful for identifying items that do not truly discriminate between unique subconstructs. The details of this test are described next. Three rounds of data collections and scale modifications were required to pass this test and establish content and discriminant validity.

\subsection{Content Adequacy Tests}

Content adequacy tests (CAT) [33, 23] are administered in the form of a matrix survey where each survey item is listed down the rows with descriptions of each construct listed across the columns. Participants must indicate how "closely" each survey items seems to "fit" within each category (e.g. by indicating $1=$ "very bad fit" to $5=$ "very good fit"). As a result, the number of participant responses is equal to the number of survey items multiplied by the number of constructs $(21$ items $\times 5$ constructs $=105$ ratings). The results of this survey are then analyzed using a repeated measures analysis of variance (rANOVA) with contrasts comparing the rating each item received for its intended construct with those of the other constructs. If the rating for the intended sub-construct is significantly higher than its rating on the others, then it has adequate content validity and discriminates among the other related sub-constructs [23].

The sample for the first round of data collection consisted of 461 responses from Amazon Mechanical Turk workers. To reduce survey fatigue bias, we randomly selected one third of the 21 items to insert into three separate versions of the survey resulting in just over 150 responses for every item. The results confirmed the failed discriminant validity analyses of the pilot data which indicated that our initial items were quite poor. Only one out of our 21 items (CA2) was valid and loaded significantly higher on its intended sub-construct than all other sub-constructs. Based on this result, we modified all but one of the items significantly. We deleted one item entirely and added two more for a new total of 22 items. In addition, we realized that our items measuring people understanding were not truly representing the definition of the construct. Therefore, we changed every item, as well as the definition within the column header, to reflect an individual's belief in their ability to understand how people will interact with potential IS solutions.

After revising the items, we collected another 467 responses from Amazon Mechanical Turk using the same 3 -survey technique to reduce fatigue. The results indicated that of the new 22 items, 11 of them were now valid (AF2, AF3, AF4, BK3, CA2, CA3, CA4, CA5, PE1, PE2, PE4) and loaded significantly higher on their own factor than all other factors. While this is an improvement, we continued to revise the remaining 12 items and made minor edits to the construct definitions for clarity. No items were added or deleted.

In the final CAT round, another 482 responses were collected from Amazon Mechanical Turk. The results indicated that 19 of the 22 items loaded significantly higher on their own factor than all other factors. The remaining three items (BK1, SK1, SK4) still loaded higher on their own factor than all other factors although they were not significantly higher than the next highest factor $(p=0.09$ to 0.16$)$. Therefore, we proceeded with Steps 7 and 8. In summary, the CAT proposed by [23, 33] proved to be a very useful technique that not only confirmed that our measurement item content was valid, but also greatly improved the CreaSE scale item discriminant validity. 


\subsection{Cross-Validation}

To cross-validate a scale, it should be administered to different, but relevant populations [33]. Sometimes, cross-validation is implemented as different cultures. However, because of the IS context of our measure, we decided to implement it across IS versus "business" job roles and IS versus business student majors. In addition, to gather an externally valid sample, it was necessary to move beyond Amazon Mechanical Turk workers. Therefore, to cross-validate the scale, we gathered data from both students and professionals including some in the IS domain and others in general business (see Table 1 for summary). The final items are available online here: http://www.gamoda.org/crease.

Because of space limitations, we do not review all of the validity and reliability tests here. However, all tests were passed with great improvements over the initial pilot tests. However, to further maximize the validity statistics, and to produce a more parsimonious scale, we removed SK4, AF1, AF5, and CA1.

\subsection{Nomological Model Testing}

The final step in MacKenzie's scale development is to validate the instrument through nomological model testing. In other words, if the instrument is nomologically valid, it should demonstrate significant relationships on variables that are theoretically modeled with the construct in question. Based on selfefficacy theory, this means that CreaSE should have positive effects on coping efforts and performance [5, 3].

To accomplish this step, we used partial least squares (PLS) structural equation modeling (SEM) to perform this step using SmartPLS 3.0 [45]. PLS-based SEM is appropriate because of the formative nature of second-order CreaSE [15].

Based on the prior CreaSE literature reviewed above, additional items were created to measure perceived coping efforts on creative tasks, and perceived performance on creative tasks. These scales were analyzed using all of the same rigorous validity analyses reported for CreaSE and passed all benchmarks. These items are also included in the online appendix. Existing scales were used to measure the personality traits openness to experience [18], risk aversion [21], and patience [30]. Additionally, age, education, and work experience were captured to represent the training, past experience, and observation of creativity in others indicated in Figure 2.

CreaSE was modeled for analysis by first calculating latent factor scores for each sub-construct.
Those scores were then used as formative indicators of the second-order factor (as recommended by prior research [33]). Figure 4 visualizes the path coefficients, bootstrapped significance tests, and $\mathrm{R}$ squared values on endogenous variables. Although not depicted in Figure 4, a control variable indicating the source of the response (IS versus business discipline, student versus professional) was also analyzed and was a significant indicator of CreaSE $(\beta=0.32, \mathrm{p}<0.001)$.

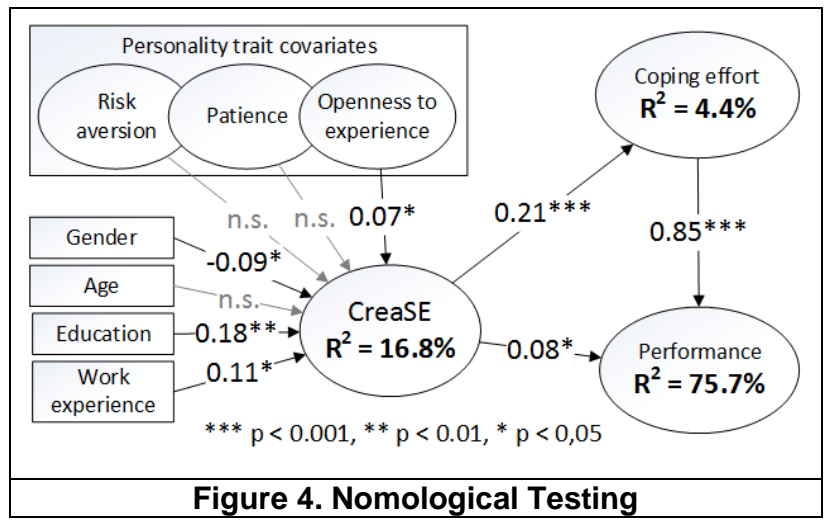

The average reported levels of CreaSE for each population were (1=lowest, $7=$ highest): IS professionals $=5.85$, business professionals $=5.48$, IS students $=5.42$, business students $=5.29$. Based on a t-statistic, the difference between each group is significant except for business professionals and IS students.

\section{Discussion}

There are several interesting findings in this study. First, it is likely that CreaSE contains several subdimensions. Affect, skills, business knowledge, people understanding, and cognition all demonstrated discriminant and convergent validity and formed a $2^{\text {nd }}$ order formative construct. In addition, this scale has been validated across several populations including students (both general business and IS majors) as well as professionals (both a professional random sample of business professionals as well as IS-specific professionals). Therefore, the primary contribution of this research is a validated scale for measuring CreaSE.

Overall, the nomological model validates the expected findings based on relevant theory from self-efficacy [3] and creativity [22] As expected, greater levels of education $(\beta=0.18, \mathrm{p}<0.01)$ and work experience $(\beta=$ $0.11, \mathrm{p}<0.05)$ - both of which would offer more opportunities for training, experience, and the observation of creative others-led to higher levels of CreaSE. In addition, women stated higher levels of CreaSE than men $(\beta=-0.09, \mathrm{p}<0.05)$.

As expected based on self-efficacy theory, CreaSE 
was positively related to both coping on creative tasks $(\beta=0.21, p<0.001)$ and performance on creative tasks $(\beta=0.08, p<0.05)$. Also, greater effort led to greater performance $(\beta=0.85, \mathrm{p}<0.001)$.

\subsection{Implications and Limitations}

Our scale for CreaSE has significant implications for research. As demonstrated, this scale can be implemented for both students and practitioners. It supports self-efficacy theory and follows guidelines for self-efficacy scales [2]. Therefore, it should be very useful to future research.

We argue that CreaSE may be one of the most important (and now measurable) outcomes of IS programs and for IS professionals. While technologies and "best-practices" will change over time, the value of a student's or professional's confidence in their ability to create unique IS solutions to business problems will likely only increase. Further, the nature of any given IS context will exude a blend of information, automation, computing, and augmentation of human capability such that the creative/innovative component may be the critical success factor. This is not a creativity bereft of competence in computing fundamentals, but rather a creativity that blends efficaciousness in the harness of computing and an understanding of what makes an information system implementation/solution resonant with its users and constituents.

The scope of this research is limited to the development of a validated scale and nomological theory testing. Therefore, future research should now use this scale to assess its ability to predict actual performance in the workplace. In addition, even our data measuring actual student performance on one exam could be expanded and improved. We recommend that future research also improve the definition of what "coping efforts on creative tasks" truly means and how it is best measured. The knowledge generated from this line of research may help IS programs and practitioners more accurately value the potential of an IS practitioner.

From a methodological perspective, our results indicate that the CAT established by [23] and suggested by [33] is a particularly useful technique. Interestingly, while the survey results after the $2^{\text {nd }}$ CAT test did not pass, that same data did pass the traditional tests for discriminant validity [16] (i.e. the AVE should be higher than the squared correlation between constructs). Therefore, although the CAT was suggested originally for content validity, we also recommend using it as a stricter measure of discriminant validity when there is a high likelihood of correlation among constructs.

\section{References}

[1] A. Baddeley, "Working memory: theories, models, and controversies", Annual review of psychology, 63 (2012), pp. 1-29.

[2] A. Bandura, Guide for constructing self-efficacy scales, in F. Pajares and T. Urdan, eds., Self-efficacy beliefs of adolescents, Information Age Publishing, Greenwhich, 2006, pp. 1-39.

[3] A. Bandura, "Self-efficacy: Toward a unifying theory of behavioral change", Psychological Review, 84 (1977), pp. 191-215. [4] A. Bandura, Social Foundations of Thought and Action, Prentice Hall, Englewood Cliffs, NJ, 1986.

[5] A. Bandura, Social Learning Theory, General Learning Press, New York, New York, USA, 1977.

[6] A. Bandura and R. Wood, "Effect of perceived controllability and performance standards on self-regulation of complex decision making", Journal of personality and social psychology, 56 (1989), pp. 805.

[7] M. S. Basadur, M. A. Runco and L. A. Vega, "Understanding how creative thinking skills attitudes and behaviors work together: A causal process model", Journal of Creative Behavior, 34 (2000), pp. $77-100$.

[8] R. A. Beghetto, "Creative self-efficacy: Correlates in middle and secondary students", Creativity Research Journal, 18 (2006), pp. 447-457.

[9] I. Blanchette and A. Richards, "The influence of affect on higher level cognition: A review of research on interpretation, judgement, decision making and reasoning", Cognition \& Emotion, 24 (2010), pp. 561-595.

[10] C. Byrge and C. Tang, "Embodied creativity training: Effects on creative self-efficacy and creative production", Thinking Skills and Creativity, 16 (2015), pp. 51-61.

[11] J. N. Choi, "Individual and contextual predictors of creative performance: The mediating role of psychological processes", Creativity Research Journal, 16 (2004), pp. 187-199.

[12] D. R. Compeau and C. A. Higgins, "Computer Self-Efficacy: Development of a Measure and Initial Test", MIS Quarterly, 19 (1995), pp. 189-211.

[13] J. M. Cortina, "What is coefficient alpha? An examination of theory and applications", Journal of applied psychology, 78 (1993), pp. 98.

[14] J. D. Couger, L. F. Higgins and S. C. McIntyre, "(Un) structured creativity in information systems organizations", Mis Quarterly (1993), pp. 375-397.

[15] J. R. Edwards, "Multidimensional constructs in organizational behavior research: An integrative analytical framework", Organizational Research Methods, 4 (2001), pp. 144-192.

[16] C. Fornell and F. L. Bookstein, "Two structural equation models: LISREL and PLS applied to consumer exit-voice theory", Journal of Marketing Research, 19 (1982), pp. 440-452.

[17] C. Fornell and D. F. Larcker, "Evaluating structural equation models with unobservable variables and measurement error", Journal of Marketing Research, 18 (1981), pp. 39-50.

[18] J. M. George and J. Zhou, "When openness to experience and conscientiousness are related to creative behavior: an interactional approach", Journal of applied psychology, 86 (2001), pp. 513.

[19] T. Goetz, H. Cronjaeger, A. C. Frenzel, O. Lüdtke and N. C. Hall, "Academic self-concept and emotion relations: Domain specificity and age effects", Contemporary Educational Psychology, 35 (2010), pp. 44-58.

[20] L. R. Goldberg, J. A. Johnson, H. W. Eber, R. Hogan, M. C. Ashton, C. R. Cloninger and H. G. Gough, "The international personality item pool and the future of public-domain personality measures", Journal of Research in Personality, 40 (2006), pp. 84-96. 
[21] Y. Gong, J.-C. Huang and J.-L. Farh, "Employee learning orientation, transformational leadership, and employee creativity: The mediating role of employee creative selfefficacy", Academy of management Journal, 52 (2009), pp. 765 778.

[22] M. R. Gover, "The Embodied Mind: Cognitive Science and Human Experience (Book)", Mind, Culture, and Activity, 3 (1996), pp. 295-299.

[23] P. H. Gray and A. Durcikova, "The role of knowledge repositories in technical support environments: Speed versus learning in user performance", Journal of Management Information Systems, 22 (2005), pp. 159-190.

[24] B. A. Hennessey and T. M. Amabile, "Creativity", Annual Review of Psychology, 61 (2010), pp. 569-598.

[25] T. R. Hinkin and J. B. Tracey, "An analysis of variance approach to content validation", Organizational Research Methods, 2 (1999), pp. 175-186.

[26] R. Hirschheim and H. K. Klein, "A glorious and not-soshort history of the information systems field", Journal of the Association for Information Systems, 13 (2012), pp. 188.

[27] R. Hirschheim, C. Saunders and D. Straub, "Historical Interpretations of the IS Discipline: An introduction to the special issue", Journal of the Association for Information Systems, 13 (2012), pp. 1-8.

[28] M. H. Hsu and C. M. Chiu, "Internet self-efficacy and electronic service acceptance", Decision Support Systems, 38 (2004), pp. 369-381.

[29] A. M. Isen and J. Reeve, "The Influence of Positive Affect on Intrinsic and Extrinsic Motivation: Facilitating Enjoyment of Play, Responsible Work Behavior, and Self-Control", Motivation and Emotion, 29 (2006), pp. 295-323.

[30] J. C. Kaufman and J. Baer, "Could Steven Spielberg manage the Yankees?: Creative thinking in different domains", Korean Journal of Thinking and Problem Solving, 12 (2002), pp. 5-14.

[31] M. J. Keith, J. S. Babb, P. B. Lowry, C. P. Furner and A. Abdullat, "The role of mobile-computing self-efficacy in consumer information disclosure", Information Systems Journal, 25 (2015), pp. 637-667.

[32] M. J. Keith, N. Ngo and J. Babb, "The effects of consumer self-regulation and risk immediacy on mobile information disclosure over time", Dewald Roode Workshop on Information Systems Security Research, IFIP WG8.11/WG11.13, Newcastle, England.

[33] M. Khan and S. Kukalis, "MIS professionals: education and performance", Information \& Management, 19 (1990), pp. 249 255.

[34] C. Koch, "How the Computer Beat the Go Master", https://www.scientificamerican.com/article/how-the-computerbeat-the-go-master/, March 18th, 2016, Accessed on February 2, 2016.

[35] S. B. MacKenzie, P. M. Podsakoff and N. P. Podsakoff, "Construct measurement and validation procedures in MIS and behavioral research: Integrating new and existing techniques", MIS quarterly, 35 (2011), pp. 293-334.

[36] G. M. Marakas, R. D. Johnson and P. F. Clay, "The evolving nature of the computer self-efficacy construct: An empirical investigation of measurement construction, validity, reliability and stability over time", Journal of the Association for Information Systems, 8 (2007), pp. 15-46.

[37] G. M. Marakas, M. Y. Yi and R. D. Johnson, "The multilevel and multifaceted character of computer self-efficacy: Toward clarification of the construct and an integrative framework for research", Information Systems Research, 9 (1998), pp. 126-163.
[38] A. L. Miller, "Creativity and cognitive style: The relationship between field-dependence-independence, expected evaluation, and creative performance", Psychology of Aesthetics, Creativity, and the Arts, 1 (2007), pp. 243-246.

[39] F. Niederman, T. W. Ferratt and E. M. Trauth, "On the coevolution of information technology and information systems personnel", ACM SIGMIS Database, 47 (2016), pp. 29-50.

[40] E. M. Okada, "Uncertainty, Risk Aversion, and WTA vs. WTP", Marketing Science, 29 (2010), pp. 75-84.

[41] J. M. Olejarz, "Liberal Arts in the Data Age", Harvard business review (2017), pp. 144-145.

[42] E. Peer, J. Vosgerau and A. Acquisti, "Reputation as a sufficient condition for data quality on Amazon Mechanical Turk", Behavior Research Methods, 46 (2014), pp. 1023-1031.

[43] D. N. Perkins and G. Salomon, "Are cognitive skills contextbound?", Educational researcher, 18 (1989), pp. 16-25.

[44] N. E. Perrine and R. Brodersen, "Artistic and scientific creative behavior: Openness and the mediating role of interests", The Journal of Creative Behavior, 39 (2005), pp. 217-236.

[45] P. M. Podsakoff, S. B. MacKenzie, J. Y. Lee and N. P. Podsakoff, "Common method biases in behavioral research: A critical review of the literature and recommended remedies", Journal of Applied Psychology, 88 (2003), pp. 879-903.

[46] A. W. Richter, G. Hirst, D. Van Knippenberg and M. Baer, "Creative self-efficacy and individual creativity in team contexts: Cross-level interactions with team informational resources", Journal of Applied Psychology, 97 (2012), pp. 1282.

[47] C. M. Ringle, S. Wende and J.-M. Becer, "SmartPLS 3", Boenningstedt: SmartPLS GmbH, http://www.smartpls.com/ (2015).

[48] J. R. A. Santos, "Cronbach's alpha: A tool for assessing the reliability of scales", Journal of extension, 37 (1999), pp. 1-5.

[49] D. A. Schön, "Generative metaphor: A perspective on problemsetting in social policy", (1993).

[50] G. Scott, L. E. Leritz and M. D. Mumford, "The effectiveness of creativity training: A quantitative review", Creativity Research Journal, 16 (2004), pp. 361-388.

[51] P. Steinbart, M. Keith and J. Babb, "Measuring Privacy Concern and the Right to Be Forgotten", Proceedings of the 50th Hawaii International Conference on System Sciences.

[52] J. B. Thatcher and P. L. Perrewe, "An empirical examination of individual traits as antecedents to computer anxiety and computer self-efficacy", MIS Quarterly, 26 (2002), pp. 381-396.

[53] P. Tierney and S. M. Farmer, "Creative self-efficacy development and creative performance over time", Journal of Applied Psychology, 96 (2011), pp. 277.

[54] P. Tierney and S. M. Farmer, "Creative self-efficacy: Its potential antecedents and relationship to creative performance", Academy of Management Journal, 45 (2002), pp. 1137-1148.

[55] A. Tiwana and E. R. Mclean, "Expertise integration and creativity in information systems development", Journal of Management Information Systems, 22 (2005), pp. 13-43.

[56] H.-L. Yang and H.-H. Cheng, "Creative self-efficacy and its factors: An empirical study of information system analysts and programmers", Computers in Human Behavior, 25 (2009), pp. 429438.

[57] C. Yu, "The relationship between undergraduate students' creative self-efficacy, creative ability and career self-management", International Journal of Academic Research in Progressive Education and Development, 2 (2013), pp. 181-193.

[58] J. Zhou and J. M. George, "When job dissatisfaction leads to creativity: Encouraging the expression of voice", Academy of Management journal, 44 (2001), pp. 682-696. 